\title{
Unexpected consequences of administering bacteriocinogenic probiotic strains for Salmonella populations, revealed by an in vitro colonic model of the child gut
}

Correspondence
Christophe Lacroix
christophe.lacroix@ilw.agrl.ethz.ch

Received 30 May 2010

Revised 19 July 2010

Accepted 29 July 2010

\author{
Annina Zihler, ${ }^{1}$ Mélanie Gagnon, ${ }^{1}$ Christophe Chassard, ${ }^{1}$ Anita Hegland, ${ }^{1}$ \\ Marc J. A. Stevens, ${ }^{1}$ Christian P. Braegger ${ }^{2}$ and Christophe Lacroix ${ }^{1}$ \\ ${ }^{1}$ Laboratory of Food Biotechnology, Institute of Food, Nutrition and Health, ETH Zürich, Zürich, \\ Switzerland \\ ${ }^{2}$ Division of Gastroenterology and Nutrition, University Children's Hospital, Zürich, Switzerland
}

\begin{abstract}
New biological strategies for the treatment of Salmonella infection are needed in response to the increase in antibiotic-resistant strains. Escherichia coli L1000 and Bifidobacterium thermophilum RBL67 were previously shown to produce antimicrobial proteinaceous compounds (microcin B17 and thermophilicin B67, respectively) active in vitro against a panel of Salmonella strains recently isolated from clinical cases in Switzerland. In this study, two three-stage intestinal continuous fermentation models of Salmonella colonization inoculated with immobilized faeces of a two-yearold child were implemented to study the effects of the two bacteriocinogenic strains compared with a bacteriocin-negative mutant of strain L1000 on Salmonella growth, as well as gut microbiota composition and metabolic activity. Immobilized E. coli L1000 added to the proximal colon reactor showed a low colonization, and developed preferentially in the distal colon reactor independent of the presence of genetic determinants for microcin B17 production. Surprisingly, E. coli L1000 addition strongly stimulated Salmonella growth in all three reactors. In contrast, $B$. thermophilum RBL67 added in a second phase stabilized at high levels in all reactors, but could not inhibit Salmonella already present at a high level $\left(>10^{7}\right.$ c.f.u. $\left.\mathrm{ml}^{-1}\right)$ when the probiotic was added. Inulin added at the end of fermentation induced a strong bifidogenic effect in all three colon reactors and a significant increase of Salmonella counts in the distal colon reactor. Our data show that under the simulated child colonic conditions, the microcin B17 production phenotype does not correlate with inhibition of Salmonella but leads to a better colonization of E. coli L1000 in the distal colon reactor. We conclude that in vitro models with complex and complete gut microbiota are required to accurately assess the potential and efficacy of probiotics with respect to Salmonella colonization in the gut.
\end{abstract}

\section{INTRODUCTION}

The human gastrointestinal tract is colonized by a complex community of micro-organisms that plays a key protective role during enteric infections (Stecher \& Hardt, 2008). Infectious gastroenteritis caused by non-typhoidal strains of Salmonella enterica subsp. enterica is an important cause of morbidity and mortality worldwide, especially in young children (Crum-Cianflone, 2008; Viswanathan et al., 2009). Due to an increasing incidence of antibiotic-resistant and more infective serovars (Kingsley et al., 2009), the use of probiotics with specific anti-Salmonella activities is of current interest. Mechanisms by which probiotics inhibit

Abbreviations: MCN, mean copy number; real-time $\mathrm{QPCR}$, real-time quantitative PCR; SCFA, short-chain fatty acid. pathogens include competition for nutritional substrates and adhesion sites on intestinal epithelial cells, toxin inactivation, as well as the secretion of antimicrobial substances (Collado et al., 2009).

Bacteriocins are promising candidates as mediators of antipathogenic probiotic effects, and their ability to inhibit pathogens in vitro is well documented (Corr et al., 2009). Corr et al. (2007), for example, showed that Lactobacillus salivarius UCC118 is able to produce the bacteriocin Abp118 in vivo, resulting in the protection of mice against Listeria monocytogenes infection. Using an ICR mouse model infected with Listeria, Dabour et al. (2009) recently showed that intragastric administration of repeated doses of pediocin PA-1 reduces Listeria counts and pathogen translocation into the liver and spleen compared with the 
infected control group, leading to the disappearance of $L$. monocytogenes in these two organs within 6 days. However, enteric protection related to in situ bacteriocin production in human gut environments has been little studied.

Using simple in vitro activity tests, we recently showed that Escherichia coli L1000 producing microcin B17 is active against a broad panel of antibiotic-resistant and -sensitive Salmonella strains isolated in Switzerland from patients suffering from salmonellosis (Zihler et al., 2009). Furthermore, thermophilicin B67, a bacteriocin-like inhibitory substance produced by the Gram-positive bacterium Bifidobacterium thermophilum RBL67 (von Ah, 2006; von Ah et al., 2007), exerts strong inhibitory activity against 10 strains of the same panel belonging to six different serovars (our unpublished data). Although simple in vitro antagonist tests are useful for screening new probiotic bacteria with specific antimicrobial activity, gut environments are much more complex. Dynamic interactions between microorganisms are responsible for colonization and competition, and in maintaining a healthy balance and the barrier effect of the gut microbiota in vivo. More elaborate models involving a complex gut microbiota providing conditions closer to those found in gastrointestinal environments are therefore required for activity and mechanistic studies of potential probiotics before considering more complex and expensive in vivo testing.

A single-stage continuous fermentation model for Salmonella colonization in the proximal colon that mimics long-term shedding in children was recently developed and used to compare the effects of antibiotic therapy and B. thermophilum RBL67 on salmonellosis in child gut environments (Le Blay et al., 2009; A. Zihler and others, unpublished results). B. thermophilum RBL67 grows in the intestinal environment and exhibits a strong inhibition of Salmonella when added before (preventive) or after (curative) Salmonella, and is able to rebalance the metabolic activity of gut microbiota after antibiotic treatments. These experiments were performed with $S$. enterica subsp. enterica serovar Typhimurium ( $S$. Typhimurium) M557, a strain lacking Salmonella pathogenicity island (SPI)-1 effector proteins, and deficient in SPI-1and SPI-2-dependent type III protein secretion systems that are known to be important host-microbe virulence factors of Salmonella (Hapfelmeier et al., 2004; Ohl \& Miller, 2001).

In the present study, we tested the effects of a combined treatment with E. coli L1000 followed by B. thermophilum RBL67 on Salmonella growth, as well as gut microbiota composition and metabolic activity, using three-stage in vitro continuous gut fermentation models (Cinquin et al., 2006) that mimic the infected child colon, employing $S$. Typhimurium $\mathrm{N}-15$, a highly invasive strain that was isolated from a clinical case (Zihler et al., 2009). E. coli L1000 was first tested by inoculating E. coli L1000 beads into the first reactor to model a colonizing E. coli strain, while the colonization and protective effect of E. coli L1000 was assumed to occur preferentially in the distal colon reactor, close to neutral pH. B. thermophilum RBL67 was inoculated in a second step to preferentially induce a protective effect in the proximal colon reactor at the lower $\mathrm{pH}$ of 5.7. Two three-stage models were operated in parallel to test comparatively the effects of E. coli L1000 wild-type $(w t)$ producing microcin B17 and the bacteriocin-negative mutant E. coli L1000 MccB17-. Finally, a prebiotic treatment with inulin was tested to stimulate $B$. thermophilum RBL67 growth.

\section{METHODS}

Bacterial strains. S. Typhimurium N-15 was isolated in 2007 from an infected person in Switzerland and obtained from the National Center for Enteropathogenic Bacteria (NENT; Luzern, Switzerland). This strain was selected for its high invasion rate into mucus-secreting intestinal HT29-MTX cells compared with other Salmonella strains obtained from clinical cases, accompanied by a high disruption of epithelial integrity as revealed by transepithelial electrical resistance (TER) measurements (our unpublished data). It was routinely cultivated in tryptic soy broth (TSB; Difco) at $37{ }^{\circ} \mathrm{C}$ for $18 \mathrm{~h}$.

E. coli L1000 wt was provided by Laves-Arzneimittel. E. coli L1000 MccB17-, lacking the microcin B17 phenotype, was constructed as described below. E. coli NCTC 50154, obtained from the UK National Collection of Type Cultures, was used as a microcin B17-sensitive indicator organism. E. coli strains were routinely grown on LuriaBertani agar (LB; Becton Dickinson) for $18 \mathrm{~h}$ at $37^{\circ} \mathrm{C}$.

B. thermophilum RBL67 (our culture collection) was routinely grown at $37{ }^{\circ} \mathrm{C}$ for $18 \mathrm{~h}$ anaerobically in de Man Rogosa Sharpe broth supplemented with $0.05 \%$ (w/v) L-cysteine HCl (MRSC; SigmaAldrich) in anaerobic jars with the AnaeroGen atmosphere generation system (Oxoid).

Mutant construction. The operon $m c b A B C D E F G$, encoding microcin $\mathrm{B} 17$ production and immunity, was chosen as a target for gene deletion using the Quick \& Easy E. coli Gene Deletion kit from Gene Bridges (BioCat) according to the manufacturer's protocol. First, a PCR product of the FRT-PGK-gb2-neo-FRT cassette containing the flanking regions of $m c b A B C D E F G$ was amplified using the primers mcbA upper and mcbG lower (Table 1). The resulting $1737 \mathrm{bp}$ product contained the FRT-PGK-gb2-neo-FRT cassette flanked by 50 bp up- and downstream regions of $m c b A B C D E F G$ introduced in the primers. The strain E. coli L1000 wt was transformed by electroporation with plasmid pRedET carrying the genes for recombination, resulting in strain E. coli L1000-pRedET. The linear FRT-PGK-gb2-neo-FRT- $m c b A B C D E F G$ fragment was transformed by electroporation into E. coli L1000-pRedET and after induction of recombination, primary integrants were selected on LB agar containing $15 \mu \mathrm{g}$ kanamycin $\mathrm{ml}^{-1}$. Integrants were checked for site-specific integration by PCR using the primer pairs mcbA upper-control/ Primer 2 (Table 1), annealing in the upstream and cassette promoter regions, and primer set Primer $3 / \mathrm{mcbG}$ lower-control, annealing in the downstream region and the kanamycin-resistance gene. The strain L1001, displaying the correct PCR profile, was cured according to the manufacturer's protocol, resulting in the mcbABCDEFG-deletion strain E. coli L1000 MccB17-. The mutant was checked for a microcin B17-negative phenotype using a modified protocol of the double-agar layer assay described by Kheadr et al. (2010). Briefly, $2 \mu \mathrm{l}$ of overnight cultures of E. coli L1000 wt and E. coli L1000 MccB17- were spotted onto the surface of LB agar $(1.5 \%, \mathrm{w} / \mathrm{v})$ and plates were left to dry aseptically for $30 \mathrm{~min}$. After incubation at $37^{\circ} \mathrm{C}$ for $18 \mathrm{~h}$, colonies were treated with $10 \mu \mathrm{l}$ chloroform (Sigma-Aldrich) for $1 \mathrm{~min}$ in closed Petri dishes and subsequently dried in opened dishes. A second layer of $15 \mathrm{ml} \mathrm{LB}$ agar $(0.8 \%, \mathrm{w} / \mathrm{v})$ seeded with $1 \%(\mathrm{v} / \mathrm{v})$ of an 
Table 1. Primers and probes used for the construction of the mutant E. coli L1000 MccB17- and the detection of different bacterial groups in faecal microbiota by real-time qPCR analysis

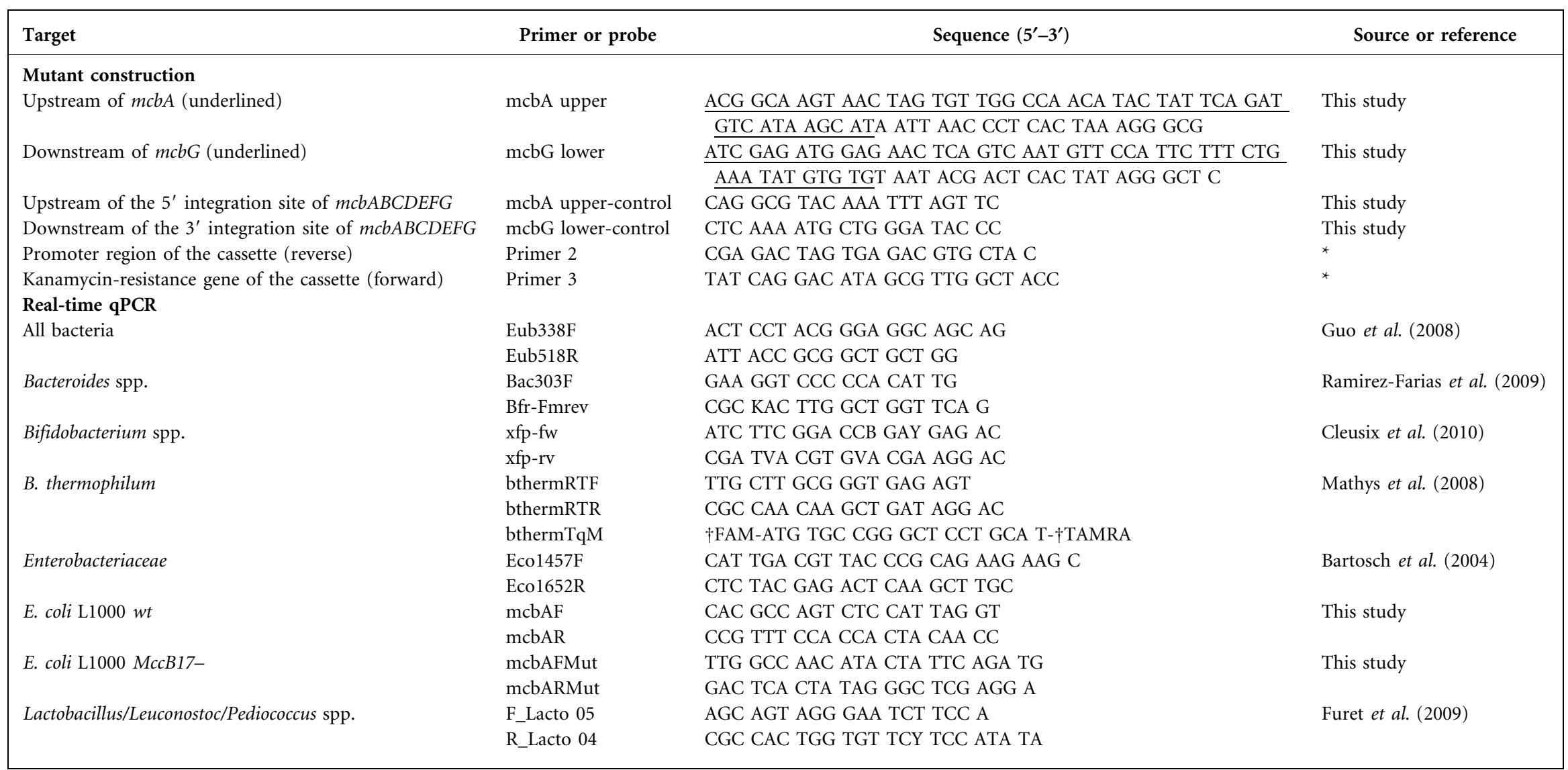

${ }^{*}$ Primers were provided within the Quick \& Easy E. coli Gene Deletion kit (Gene Bridges GmbH).

†FAM, 6-carboxyfluorescein (fluorescent reporter dye); TAMRA, 6-carboxytetramethylrhodamine (quencher). 
overnight culture of the indicator strain E. coli NCTC 50154 or $S$. Typhimurium N-15 was poured on the plates. After agar solidification, plates were incubated at $37{ }^{\circ} \mathrm{C}$ for $18 \mathrm{~h}$ and checked for the absence of inhibition zones.

Bacterial immobilization. A faecal sample ( $\sim \mathrm{g})$ from a healthy 2year-old child (male), receiving a fully diversified diet and not exposed to antibiotic therapy for at least 3 months before the experiment, was collected. The sample was transferred to a tube containing $5 \mathrm{ml}$ sterile, pre-reduced peptone water $(0.1 \%, \mathrm{pH} 7)$, placed in an anaerobic jar, and immediately delivered to the laboratory before being homogenized. The faecal suspension was weighed and the volume adjusted with peptone water to obtain a final faecal concentration of $20 \%(\mathrm{w} / \mathrm{v})$. The faecal bacterial extract was immobilized in 1-2 mm diameter gel beads composed of $2.5 \%$ gellan gum, $0.25 \%$ xanthan gum and $0.2 \%$ sodium citrate (w/v, SigmaAldrich), as described previously (Cleusix et al., 2008; Le Blay et al., 2009). The entire process was performed under anaerobic conditions within $3 \mathrm{~h}$ after defecation. An inoculum of $60 \mathrm{ml}(30 \%, \mathrm{v} / \mathrm{v})$ of fresh faecal beads was immediately transferred to the first reactors of both three-stage fermentation systems.

Ten-fold-concentrated overnight cultures of S. Typhimurium N-15, E. coli L1000 wt, E. coli L1000 MccB17- and B. thermophilum RBL67 were separately immobilized in the same way but aerobically. Bead colonization was performed with batch cultures in TSB for Salmonella $\left(18 \mathrm{~h}, 37{ }^{\circ} \mathrm{C}\right.$, no pH control), in LB for E. coli $\left(18 \mathrm{~h}, 37^{\circ} \mathrm{C}\right.$, no pH control) and in MRSC for B. thermophilum RBL67 $\left(24 \mathrm{~h}, 40{ }^{\circ} \mathrm{C}\right.$, $\mathrm{pH}$ 6.0, stirring at 150 r.p.m.). Colonized beads were washed in sterile $\mathrm{CaCl}_{2}\left(0.1 \mathrm{~mol} \mathrm{l}^{-1}\right)$ and used to inoculate the first or third reactor of the appropriate fermentation system, as described below.

Nutritive culture medium. A complex culture medium simulating the intestinal chyme of a young child was used to feed the first reactor of each three-stage fermentation system. The medium was similar to that described by Macfarlane et al. (1998) and modified for children by reducing the bile salt concentration from 0.4 to $0.05 \mathrm{~g} \mathrm{l}^{-1}$ in order to reproduce the ileal chyme of a young child (Le Blay et al., 2009). A $0.5 \mathrm{ml}$ volume of a filter-sterilized (Minisart, $0.2 \mu \mathrm{m}$ pore-size, Sartorius) vitamin solution (Michel et al., 1998) was added to 11 of the autoclaved $\left(15 \mathrm{~min}, 121{ }^{\circ} \mathrm{C}\right)$ medium. For prebiotic treatments, the medium was supplemented with $15 \mathrm{~g} \mathrm{l}^{-1}$ high-solubility inulin (Orafti HIS, Beneo Orafti) before autoclaving.

Fermentation procedures. Faecal bead colonization was performed during batch fermentations for $48 \mathrm{~h}$ in two reactors (Sixfors, Infors) containing $30 \%$ fresh beads and operated at a working volume of
$200 \mathrm{ml}$ at $\mathrm{pH} 5.7$ and $37^{\circ} \mathrm{C}$, as previously described (Le Blay et al., 2009). The fermented medium was replaced every $12 \mathrm{~h}$ with fresh nutritive medium. Then, two additional reactors (R2 and R3), halffilled with sterile nutritive medium, were connected in series to the first reactor, R1. Continuous fermentation was started by connecting a stirred feedstock vessel containing sterile nutritive medium $\left(4{ }^{\circ} \mathrm{C}\right)$ via peristaltic pumps (Reglo Analog, Ismatec) to R1. Fermented medium from $\mathrm{R} 1$ was then pumped to $\mathrm{R} 2$ (working volume $400 \mathrm{ml}$ ), from R2 to R3 (working volume $400 \mathrm{ml}$ ), and finally from R3 to an effluent receiving vessel. The retention times and $\mathrm{pH}$ in $\mathrm{R} 1, \mathrm{R} 2$ and $\mathrm{R} 3$ were selected to mimic in vivo conditions in the child proximal, transverse and distal colons (Fallingborg et al., 1990; Wagener et al., 2004). The total mean retention time of the system with a total volume of $800 \mathrm{ml}$ was set at $25 \mathrm{~h}$ by adjusting the feed flow rate to $40 \mathrm{ml} \mathrm{h}^{-1}$, resulting in mean retention times of $5 \mathrm{~h}$ for $\mathrm{R} 1$ and $10 \mathrm{~h}$ for R2 and R3. The headspaces of the reactors were continuously flushed with $\mathrm{CO}_{2}$ to maintain anaerobic conditions. The $\mathrm{pH}$ in $\mathrm{R} 1, \mathrm{R} 2$ and R3 was automatically controlled at pH 5.7, 6.2 and 6.7, respectively, by adding $5 \mathrm{M} \mathrm{NaOH}$.

The two three-stage reactor models (F1 and F2) were operated in parallel for a total of 65 days, which was divided into different periods, as shown in Fig. 1. After bead colonization and stabilization for 10 days (Stab), S. Typhimurium N-15 beads $\left(2.3 \times 10^{9}\right.$ c.f.u. $\left.\mathrm{g}^{-1}\right)$ were added twice to the first reactor (R1) of both models ( $2 \mathrm{~g}$ on day 13 and $2.5 \mathrm{~g}$ on day 17) to induce Salmonella colonization. Continuous culture was carried out until day 22 (Sal). Beads containing the microcin B17producing wild-type strain of E. coli (L1000 wt) were added on day 22 to R1 of F1 ( 5 g, $1.5 \times 10^{9}$ c.f.u. $\mathrm{g}^{-1}$, Ecol I) and repeated on day 36 in R3 (5 g, $1.4 \times 10^{9}$ c.f.u. $\mathrm{g}^{-1}$, Ecol II). For F2, the same protocol was applied but the wild-type $E$. coli strain was replaced by the mutant $E$. coli L1000 MccB17-, which did not produce microcin B17. On day 44, $5 \mathrm{~g} \mathrm{~B}$. thermophilum RBL67 beads $\left(3.4 \times 10^{10}\right.$ c.f.u. $\left.\mathrm{g}^{-1}\right)$ were added to R1 of both models (F1, Bif I; F2, Bif). This treatment was repeated on day 56 in the first fermentation model (F1, Bif II), while in the second fermentation model (F2), the nutritive medium was supplemented instead with $15 \mathrm{~g}$ inulin per day during the last fermentation period (Inulin). Effluents $(13 \mathrm{ml})$ were simultaneously sampled daily in the morning from each reactor and processed within $1 \mathrm{~h}$ for the enumeration of $S$. Typhimurium N-15 by selective plating and of bacterial populations by real-time quantitative PCR (real-time qPCR) analysis, and for HPLC measurements.

Salmonella enumeration by plate counts. Serial 10 -fold dilutions of effluent samples were carried out in peptone water $(0.1 \%, \mathrm{pH} 7.0)$ and plated daily in duplicate on CHROMagar Salmonella medium (Becton Dickinson). Plates were incubated aerobically at $37^{\circ} \mathrm{C}$ for $48 \mathrm{~h}$.

Fermentation 1 (F1)

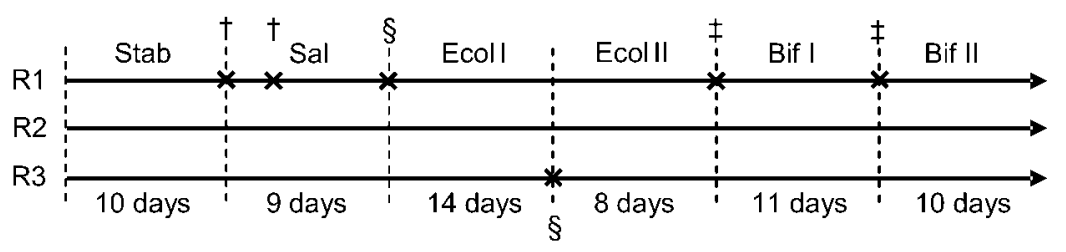

Fermentation 2 (F2)

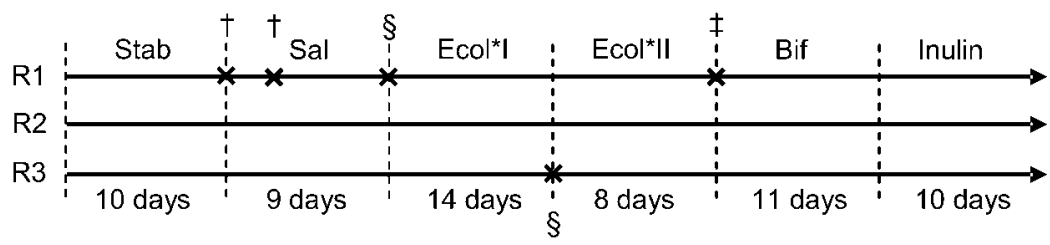

Fig. 1. Experimental design for continuous intestinal fermentations. Stab, stabilization; Sal, S. Typhimurium N-15; Ecol I and Ecol II, E. coli L1000 wt; Ecol*I and Ecol*II, E. coli L1000 MccB17-; Bif, Bif I and Bif II, B. thermophilum RBL67; Inulin, inulin period. tAddition of $S$. Typhimurium $\mathrm{N}-15$ beads; §addition of $E$. coli L1000 beads; faddition of $B$. thermophilum RBL67 beads. 
Analysis of gut microbiota populations using real-time qPCR. Genomic DNA was extracted from $1.5 \mathrm{ml}$ effluent samples with the FastDNA SPIN Kit for Soil (MP Biomedicals) according to the manufacturer's instructions, with a final elution volume of $100 \mu \mathrm{l}$. Primer sets used for different bacterial groups in this study (Microsynth) are listed in Table 1. Primers used for the enumeration of E. coli L1000 wt and E. coli L1000 MccB17- were designed using the Primer3 Input software (version 0.4.0; http://frodo.wi.mit.edu/ primer3) based on the $m c b A B C D E F G$ operon sequence (EMBL accession no. FM877811) and the sequence in the mutant strain after removal of the selection marker. Primers were checked for $T_{\mathrm{m}}$ (melting temperature), secondary structure formation, $\mathrm{G}+\mathrm{C}$ content and primer-dimer formation using the PCR Primer Stats software (http://www.bioinformatics.org/sms2/pcr_primer_stats.html).

PCR amplification and detection were performed with an ABI PRISM 7500-PCR sequence detection system (Applied Biosystems) in MicroAmp Fast Optical 96-Well Reaction Plates with Barcode (Applied Biosystems). Each reaction was run in duplicate and took place in a total volume of $25 \mu \mathrm{l}$, containing $12.5 \mu \mathrm{l} 2 \times$ SYBR Green PCR Master Mix (Applied Biosystems), $0.2 \mu \mathrm{mol} 1^{-1}$ of the appropriate primers, and $1 \mu \mathrm{l}$ template DNA diluted 10 - or 100 fold depending on the targeted bacterial group. For the detection of $B$. thermophilum RBL67, reaction mixtures were composed of $12.5 \mu 1$ qPCR MasterMix Plus LowRox (Eurogentec), $2.5 \mu$ l template DNA diluted 10 -fold, $0.3 \mu \mathrm{mol} 1^{-1}$ of each primer and $0.1 \mu \mathrm{mol} 1^{-1}$ TaqMan probe. Real-time $\mathrm{qPCR}$ conditions were kept at the presettings of the ABI PRISM 7500-PCR sequence detection system, with an initial heating step of $2 \mathrm{~min}$ at $50^{\circ} \mathrm{C}$ and a denaturation step of $10 \mathrm{~min}$ at $95{ }^{\circ} \mathrm{C}$, followed by 40 amplification cycles of $95{ }^{\circ} \mathrm{C}$ for $15 \mathrm{~s}$ and $60{ }^{\circ} \mathrm{C}$ for $1 \mathrm{~min}$. A final dissociation step was added for SYBR Green amplifications to improve amplification specificity. The fluorescent products were detected during the second step of each cycle. Melting curve analysis was performed after amplification using the 7500 Fast system SDS Software (version 1.4, Applied Biosystems) to evaluate the specificity of the primers and quality of the PCR. A standard curve for each primer pair was analysed in the same run and used for calculation of the number of $16 \mathrm{~S}$ rDNA or gene copies detected in each sample. Mean copy number per millilitre effluent $\left(\mathrm{MCN} \mathrm{ml}{ }^{-1}\right)$ was calculated for the last 3 days of each period.

Metabolite analysis. Short-chain fatty acid (SCFA; acetate, propionate and butyrate) concentrations in effluent samples were determined by HPLC analysis, as described previously (Cleusix et al., 2008).

Statistical analysis. All statistical analyses were performed using the statistical software JMP 8.0 for Windows (SAS Institute). Cell counts and $\mathrm{MCN} \mathrm{ml}^{-1}$ values were $\log _{10}$-transformed to stabilize the variance and normalize the residual values for variance homogeneity.

The significance of slopes and intercepts of regression curves of logtransformed Salmonella cell concentrations in effluent samples versus time were tested for their difference from 0 using the $t$ test $(P<0.05)$. A multivariate analysis of variance (MANOVA) was performed to compare slopes of trend lines between reactors using the $F$ test $(P<0.05)$.

A one-way analysis of variance (ANOVA) was performed to test differences between mean metabolite concentrations measured by HPLC in effluent samples collected for the last 3 days of the experiment. An ANOVA was performed to test the effects of different treatments on mean log-transformed cell counts of Salmonella measured by selective plating and mean log-transformed $\mathrm{MCN} \mathrm{ml}{ }^{-1}$ of E. coli L1000 wt or MccB17- and B. thermophilum RBL67 (mean of the last 3 days of the periods), and on mean log-transformed MCN $\mathrm{ml}^{-1}$ of intestinal bacterial groups (mean of the last 3 days and three reactors) detected by real-time qPCR analyses. Means were compared using the Tukey-Kramer HSD test with a probability level of $P<0.05$.

\section{RESULTS}

\section{Mutant construction}

The microcin B17 activity of E. coli L1000 wt and its mutant MccB17- was tested with the double-agar layer assay (Fig. 2). E. coli L1000 wt was highly active against the indicator organism E. coli NCTC 50154 and also inhibited $S$. Typhimurium N-15. In contrast, no inhibition was detected for the mutant strain E. coli L1000 MccB17- with both indicator strains.

\section{Colonization of E. coli L1000 and B. thermophilum RBL67}

The $\log _{10}\left(\mathrm{MCN} \mathrm{ml} \mathrm{ml}^{-1}\right)$ of intestinal populations was measured by real-time qPCR analysis and calculated for the last 3 days of each fermentation period. The $\mathrm{MCN}$ values for Enterobacteriaceae and Bifidobacterium spp. and subpopulations of E. coli L1000 and B. thermophilum RBL67 are shown in Figs 3 and 4, respectively.

No signal was detected for E. coli L1000 wt and MccB17- in effluent samples before addition to F1 and F2, respectively. After adding $5 \mathrm{~g} \mathrm{E}$. coli L1000 wt (F1) and MccB17- (F2) beads to R1 (Ecol I and Ecol ${ }^{\star} \mathrm{I}$ ), MCN values were $1-1.5 \mathrm{log}$ units higher for E. coli L1000 wt compared with MccB17-, which was significant only in $\mathrm{R} 2$ and $\mathrm{R} 3(P<0.05)$. A second addition of E. coli L1000 beads to R3 in both systems led to a significant $(P=0.011)$ increase of $E$. coli L1000 counts in the effluent of R3 only for the mutant strain MccB17- (F2), with no effect for E. coli L1000 wt. Counts of E. coli L1000 wt decreased in both R1 and R2, and increased in R3 $(P<0.05)$ by approximately $1 \log$ unit after adding $B$. thermophilum RBL67 to R1 (Bif I). In contrast, no change of E. coli L1000 counts was observed for the mutant strain MccB17- (Bif in

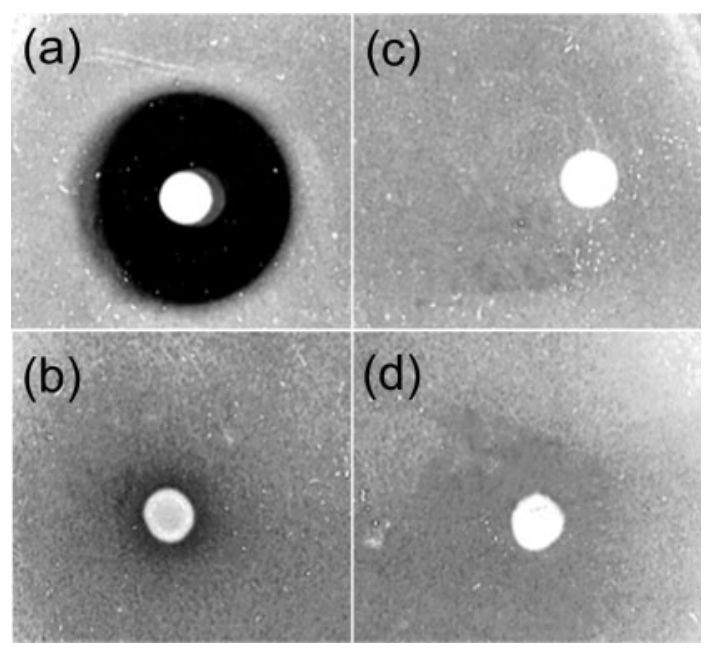

Fig. 2. Double-agar layer activity assays for $E$. coli L1000 wt $(\mathrm{a}, \mathrm{b})$ and E. coli L1000 MccB17- (c, d) against target organisms E. coli NCTC 50154 (a, c) and S. Typhimurium N-15 (b, d). 
Fermentation periods (F1)
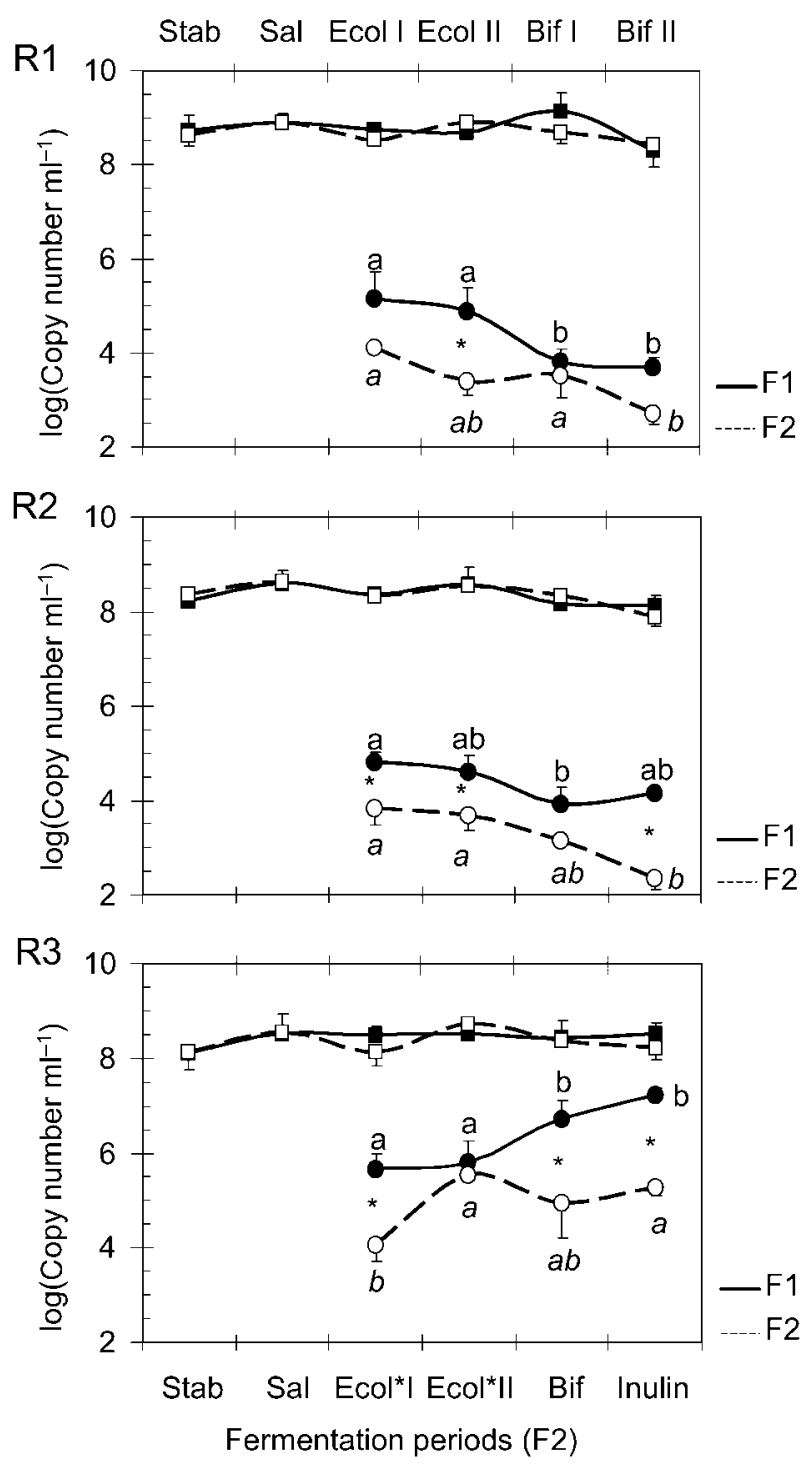

Fig. 3. Mean concentrations of Enterobacteriaceae $(\boldsymbol{\square}, \square)$, E. coli L1000 wt (O) and E. coli L1000 MccB17- (O) in effluent samples of the proximal (R1), transverse (R2) and distal (R3) colon reactors of F1 (filled symbols) and F2 (open symbols) measured by real-time qPCR, expressed as $\log _{10}\left(\mathrm{MCN} \mathrm{ml}{ }^{-1}\right.$ ) (mean of last 3 days of the period). Period means with different letters are significantly different within F1 (roman type) and F2 (italic type), respectively, with the Tukey-Kramer HSD test $(P<0.05)$. Asterisks signify that means for the corresponding periods of $F 1$ and $\mathrm{F} 2$ are significantly different with the $F$ test.

F2) and after a second addition of B. thermophilum RBL67 to R1 (Bif II in F1). Inulin addition ('Inulin' in F2) induced a decrease of E. coli L1000 MccB17- counts in R1 and R2 (only significant for R1), with no change recorded in F3.

B. thermophilum RBL67 was not detected in effluent samples of F1 and F2 before addition to R1. After adding $5 \mathrm{~g} \mathrm{~B}$. thermophilum RBL67 beads to R1, counts of $B$.
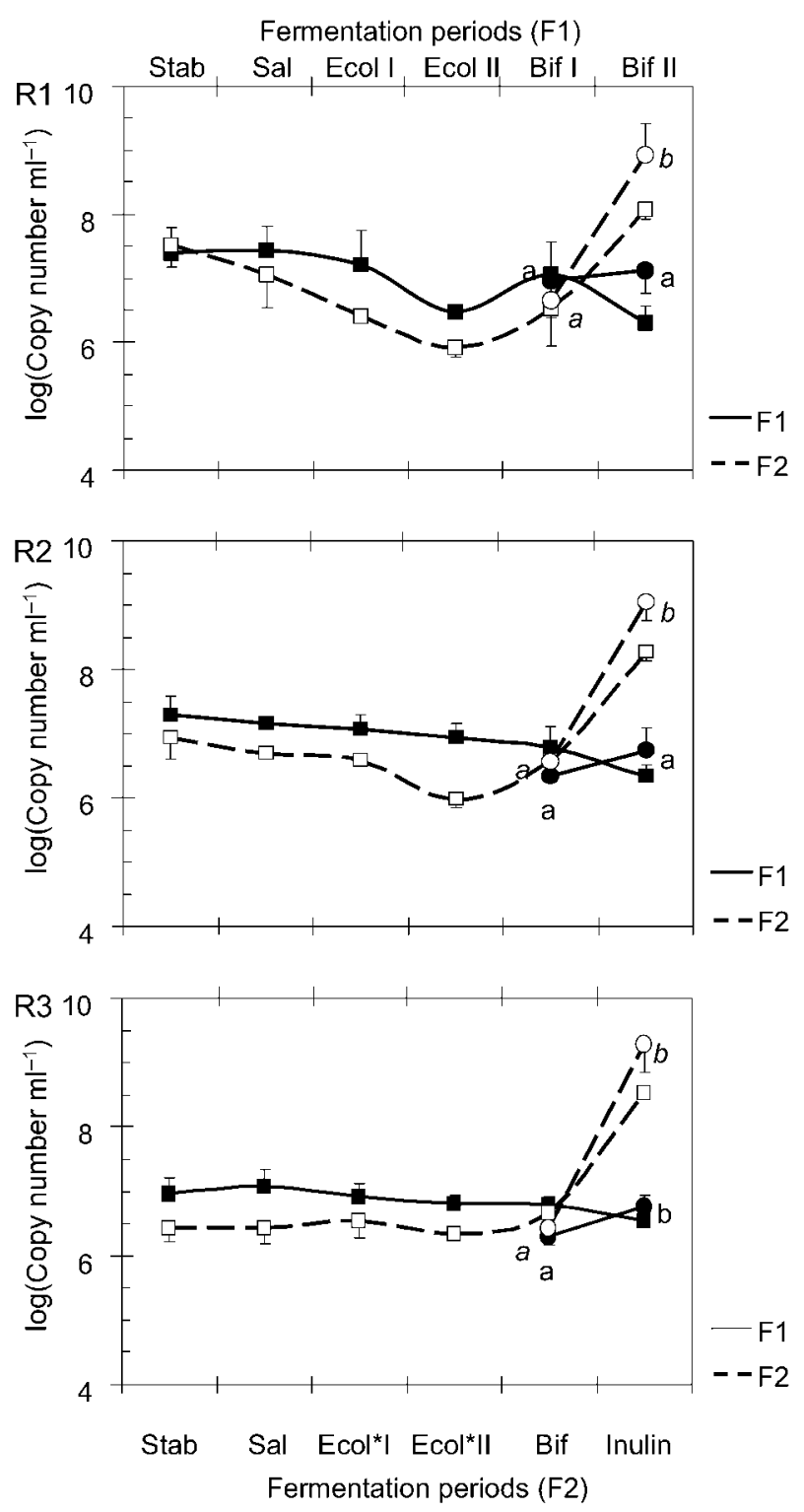

Fig. 4. Mean concentrations of Bifidobacterium spp. $(\boldsymbol{\square}, \square)$ and B. thermophilum RBL67 $(\bullet, \bigcirc)$ in effluent samples of the proximal (R1), transverse (R2) and distal (R3) colon reactors of F1 (filled symbols) and F2 (open symbols) measured by real-time qPCR, expressed as $\log _{10}\left(\mathrm{MCN} \mathrm{ml}^{-1}\right)$ (mean of last 3 days of the period). Period means with different letters are significantly different within F1 (roman type) and F2 (italic type), respectively, with the TukeyKramer HSD test $(P<0.05)$.

thermophilum RBL67 reached similar high values in all reactors of $\mathrm{F} 1$ and $\mathrm{F} 2$, with respective mean values for $\log _{10}\left(\mathrm{MCN} \mathrm{ml}{ }^{-1}\right)$ of $6.5 \pm 0.4$ (Bif I) and $6.5 \pm 0.1$ (Bif). After a second addition of $B$. thermophilum RBL67 beads to R1 of F1 (Bif II), counts only increased significantly $(P=0.035)$ in $\mathrm{R} 3$ compared with the previous period (Bif I), whereas no effect was detected for R1 and R2. Addition of inulin to the growth medium led to a sharp and significant $(P<0.007)$ increase of $B$. thermophilum RBL67 
counts in all reactors of $\mathrm{F} 2$ of up to $3 \log _{10}\left(\mathrm{MCN} \mathrm{ml}^{-1}\right)$ units.

\section{Effects of probiotic and prebiotic treatments on Salmonella propagation}

Daily Salmonella concentrations determined by selective plating during 65-day fermentations in F1 and F2 are presented in Fig. 5, and mean concentrations detected during the last 3 days of each fermentation period are displayed in Table 2.

After the first addition of $2 \mathrm{~g} S$. Typhimurium N-15 beads, Salmonella was detected in the effluents of all reactors after 1 day but decreased steadily thereafter. A second addition of $2.5 \mathrm{~g}$ S. Typhimurium N-15 beads was performed and a continuous increase of Salmonella counts was recorded in all reactors of F1 and F2, reaching at the end of the Salmonella stabilization period (Sal) higher levels in R1 and R2 compared with R3, with means of $5.8 \pm 0.3,5.6 \pm 0.5$ and $4.3 \pm 0.5 \log$ c.f.u. $\mathrm{ml}^{-1}$, respectively.

Effects of E. coli L1000. The addition of $5 \mathrm{~g}$ E. coli L1000 $w t$ or MccB17- beads to R1 further stimulated Salmonella growth during the following 14-day period in F1 and F2 (Fig. 5). Salmonella counts increased linearly with time $(P<0.0001)$ in all reactors, with a higher rate in $\mathrm{R} 2$ compared with R1 and R3 for both models. A second addition of $5 \mathrm{~g}$ E. coli L1000 beads in the distal reactor (R3) of F1 and F2 on day 36 had no significant effect on Salmonella counts in the reactor effluent (Ecol II and Ecol $^{\star}$ II). After E. coli L1000 addition, Salmonella counts in
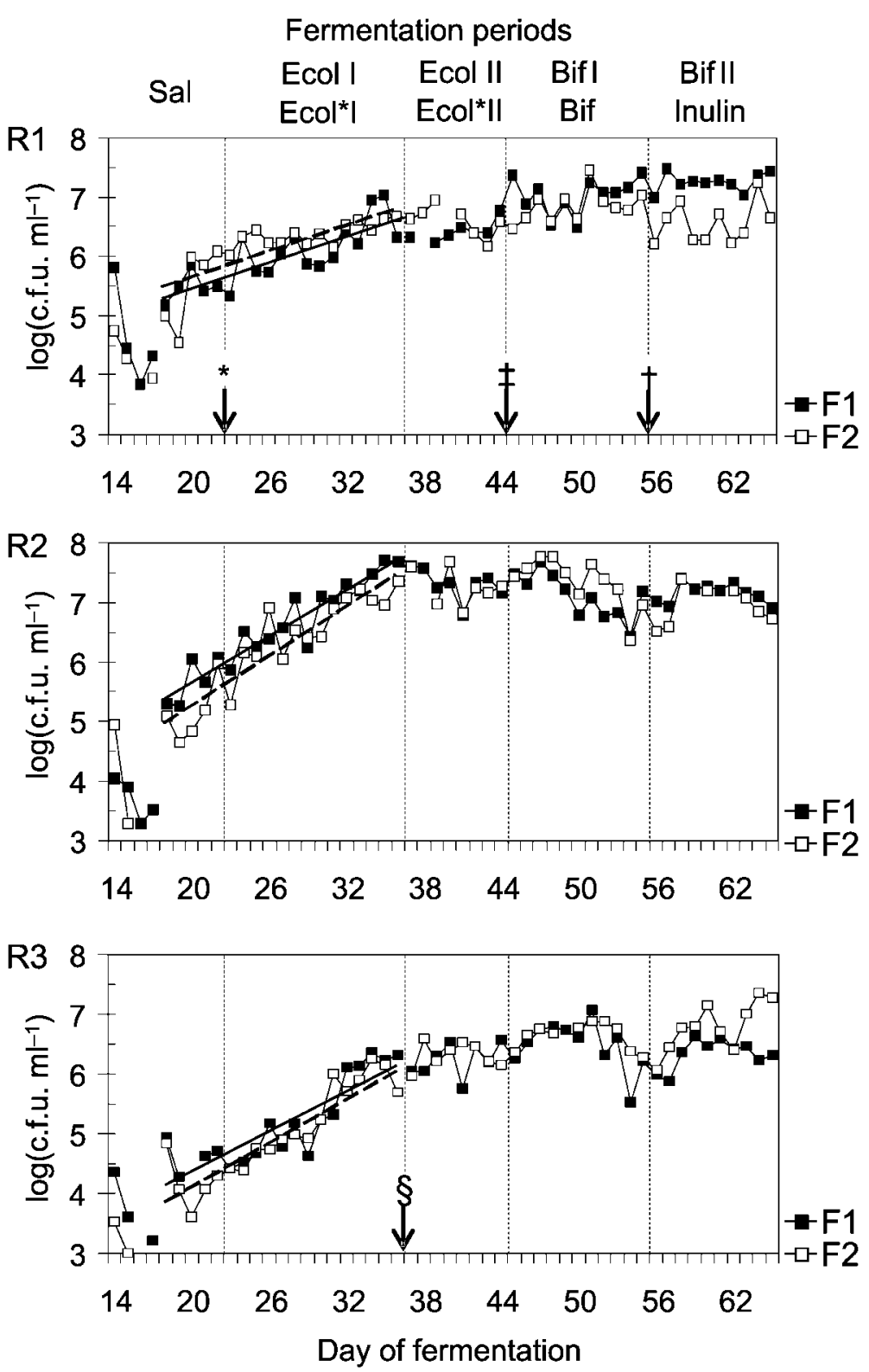

Fig. 5. Salmonella concentrations, as $\log _{10}[\text { c.f.u. (ml effluent) })^{-1}$, measured daily by plate counts in effluents of the proximal (R1), transverse (R2) and distal (R3) colon reactors of fermentations F1 and F2. Regression lines were calculated over the time period from day 14 to 37 for F1 (solid lines) and F2 (dashed lines). * and $\S$, addition of $5 \mathrm{~g} \mathrm{E}$. coli L1000 wt and E. coli L1000 MccB17- beads to F1 and $\mathrm{F} 2$, respectively; faddition of $5 \mathrm{~g} \mathrm{~B}$. thermophilum RBL67 beads; taddition of $5 \mathrm{~g} B$. thermophilum RBL67 beads to F1 and start of nutritive medium supplementation with inulin (15 g per day) for F2. 
Table 2. Salmonella counts $\left[\log _{10}\right.$ (c.f.u. $\mathrm{ml}^{-1}$ )] obtained by selective plating on CHROMagar Salmonella medium for different fermentation periods of continuous cultures in $\mathrm{F} 1$ and F2

Data are reported as mean \pm SD of three reactors for the last 3 days. Values with different letters in a column are significantly different by the Tukey-Kramer HSD test or the $F$ test $(P<0.05)$. ND, Not detected.

\begin{tabular}{|lccc|}
\hline Period & R1 & R2 & R3 \\
\hline F1 & & & \\
Stab & ND & ND & ND \\
Sal & $5.6 \pm 0.2^{\mathrm{c}}$ & $5.9 \pm 0.2^{\mathrm{c}}$ & $4.7 \pm 0.1^{\mathrm{b}}$ \\
Ecol I & $6.8 \pm 0.4^{\mathrm{ab}}$ & $7.6 \pm 0.1^{\mathrm{a}}$ & $6.3 \pm 0.1^{\mathrm{a}}$ \\
Ecol II & $6.5 \pm 0.2^{\mathrm{b}}$ & $7.3 \pm 0.1^{\mathrm{ab}}$ & $6.4 \pm 0.2^{\mathrm{a}}$ \\
Bif I & $7.2 \pm 0.2^{\mathrm{ab}}$ & $6.8 \pm 0.4^{\mathrm{b}}$ & $6.1 \pm 0.6^{\mathrm{a}}$ \\
Bif II & $7.3 \pm 0.2^{\mathrm{a}}$ & $7.1 \pm 0.1^{\mathrm{ab}}$ & $6.3 \pm 0.1^{\mathrm{a}}$ \\
F2 & & & \\
Stab & $\mathrm{ND}$ & $\mathrm{ND}$ & $\mathrm{ND}$ \\
Sal & $6.0 \pm 0.1^{\mathrm{b}}$ & $5.3 \pm 0.6^{\mathrm{b}}$ & $4.0 \pm 0.4^{\mathrm{c}}$ \\
Ecol ${ }^{\star} \mathrm{I}$ & $6.6 \pm 0.1^{\mathrm{ab}}$ & $7.1 \pm 0.2^{\mathrm{a}}$ & $6.0 \pm 0.3^{\mathrm{b}}$ \\
Ecol ${ }^{\star} \mathrm{II}$ & $6.4 \pm 0.2^{\mathrm{ab}}$ & $7.2 \pm 0.1^{\mathrm{a}}$ & $6.3 \pm 0.2^{\mathrm{b}}$ \\
Bif & $6.9 \pm 0.1^{\mathrm{a}}$ & $6.8 \pm 0.4^{\mathrm{a}}$ & $6.5 \pm 0.3^{\mathrm{b}}$ \\
Inulin & $6.8 \pm 0.4^{\mathrm{a}}$ & $6.9 \pm 0.2^{\mathrm{a}}$ & $7.2 \pm 0.2^{\mathrm{a}}$ \\
\hline
\end{tabular}

all reactors of F1 and F2 were equal or higher to 6.0 $\log _{10}$ (c.f.u. $\mathrm{ml}^{-1}$ ) (Table 2).

Effects of $B$. thermophilum RBL67. Addition of $5 \mathrm{~g} \mathrm{~B}$. thermophilum RBL67 beads on day 44 to R1 showed no significant effects on Salmonella counts in all three reactors of F1 and F2, which were in the range from $6.1 \pm 0.6$ to $7.2 \pm 0.2 \log _{10}$ (c.f.u. $\mathrm{ml}^{-1}$ ) during the last 3 days of the Bif I (F1) and Bif (F2) periods (Table 2). Subsequent addition of $5 \mathrm{~g} \mathrm{~B}$. thermophilum RBL67 beads to R1 on day 55 had no significant effect on Salmonella counts (Bif II, F1) compared with the previous Bif I period.

Effects of inulin. Supplementation of the nutritive medium with inulin during the final experimental period of F2 (Inulin) led to significantly $(P=0.037)$ increased levels of Salmonella in R3, with no detectable effects in R1 and R2.

\section{Effects of Salmonella, probiotic and prebiotic treatments on main gut microbiota populations}

MCN (ml effluent) ${ }^{-1}$ values of intestinal populations measured by real-time qPCR during the last 3 days of each experimental period were not significantly different for the proximal, transverse and distal reactors. Therefore, the mean MCN values calculated for the three reactors are presented in Table 3.

Independent of the experimental period, high and stable counts of total bacteria were detected in all reactors of both models, with high values in the range $2.6 \times 10^{10}-5.8 \times 10^{10}$ and $1.5 \times 10^{10}-4.7 \times 10^{10} \mathrm{MCN} \mathrm{ml}^{-1}$ measured for $\mathrm{F} 1$ and F2, respectively, during 65 days of continuous culture. Bacteroides spp. was the predominant bacterial group, followed by Enterobacteriaceae, Bifidobacterium spp. and Lactobacillus/Leuconostoc/Pediococcus spp. Counts of Bacteroides spp. were stable overall during the experiment in $\mathrm{F} 1$ and F2, except for the final inulin period in R1 of F2,

Table 3. $\log _{10}\left(\mathrm{MCN} \mathrm{ml}^{-1}\right)$ values for intestinal populations measured by real-time qPCR in faecal inoculum and fermentation effluent samples for different periods of fermentations F1 and F2

Data are means \pm SD of three reactors calculated for the last 3 days of each fermentation period. Values with different letters in a column of the same reactor are significantly different by the Tukey-Kramer HSD test $(P<0.05)$.

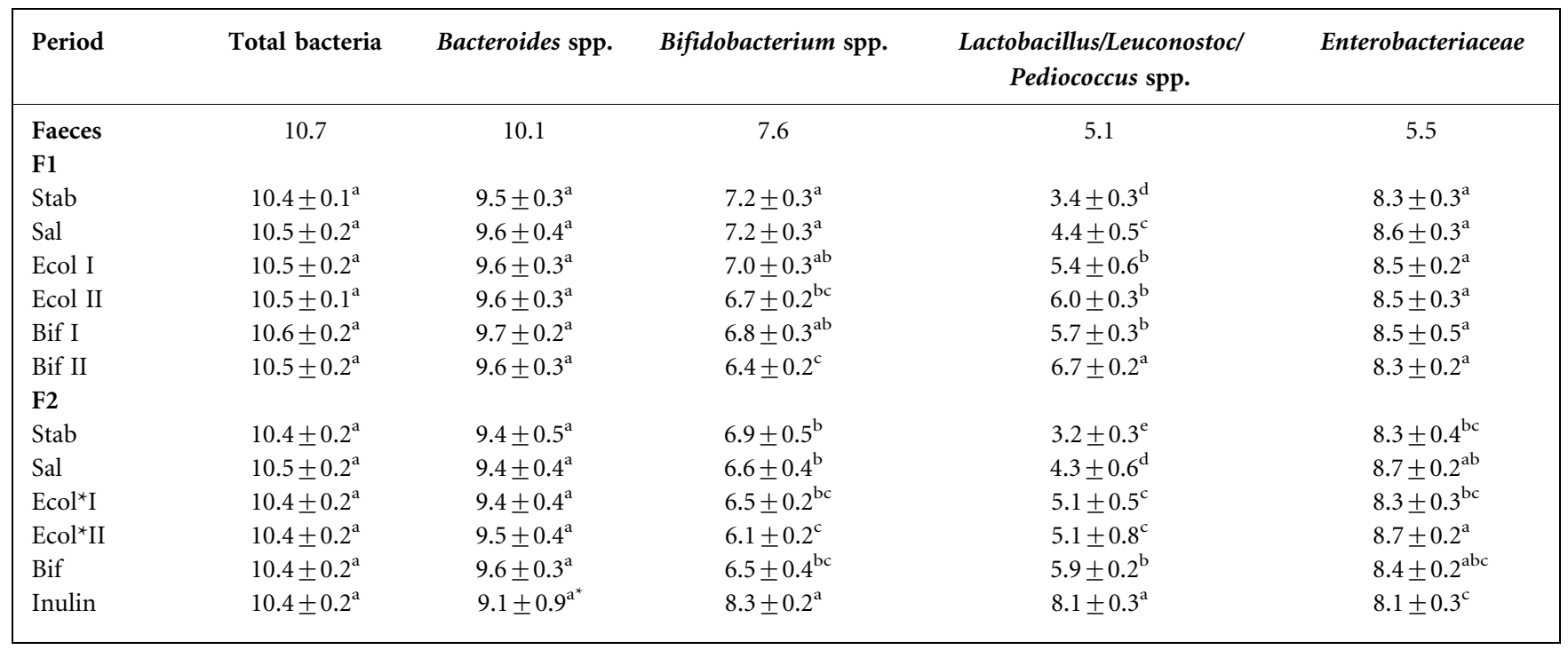

${ }^{\star} \log _{10}\left(\mathrm{MCN} \mathrm{ml}^{-1}\right)$ values were significantly lower in $\mathrm{R} 1(8.0 \pm 0.4)$ than in $\mathrm{R} 2(9.7 \pm 0.3)$ and $\mathrm{R} 3(9.8 \pm 0.1)$. 
Table 4. Mean SCFA concentrations ( $\mathrm{mmol} \mathrm{I}^{-1}$ ) and SCFA ratios in effluents sampled from the proximal (R1), transverse (R2) and distal (R3) colon reactors of fermentations F1 and F2

Data are means \pm SD and ratios (in parentheses) calculated for the last 3 days of each fermentation period and for the overall experiment. Values with different letters in a column of the same reactor are significantly different by the Tukey-Kramer HSD test $(P<0.05)$.

\begin{tabular}{|lcccc|}
\hline Reactor & Total SCFA & Acetate & Butyrate & Propionate \\
\hline F1 & & & \\
R1 & $140.6 \pm 5.5^{\mathrm{c}}$ & $76.7 \pm 4.7^{\mathrm{c}}(55)$ & $46.2 \pm 3.8^{\mathrm{c}}(33)$ & $17.7 \pm 2.5^{\mathrm{c}}(13)$ \\
R2 & $171.2 \pm 5.3^{\mathrm{b}}$ & $93.3 \pm 4.6^{\mathrm{b}}(54)$ & $53.1 \pm 3.7^{\mathrm{b}}(31)$ & $24.8 \pm 3.3^{\mathrm{b}}(14)$ \\
R3 & $190.1 \pm 8.5^{\mathrm{a}}$ & $104.4 \pm 5.7^{\mathrm{a}}(55)$ & $56.7^{\mathrm{a}} \pm 4.7^{\mathrm{a}}(30)$ & $29.0 \pm 2.4^{\mathrm{a}}(15)$ \\
F2 & & & \\
R1 & $142.6 \pm 17.6^{\mathrm{b}}$ & $74.0 \pm 6.1^{\mathrm{b}}(52)$ & $55.8 \pm 15.9^{\mathrm{a}}(39)$ & $12.8 \pm 2.0^{\mathrm{c}}(9)$ \\
R2 & $184.7 \pm 28.2^{\mathrm{a}}$ & $94.2 \pm 7.8^{\mathrm{a}}(53)$ & $62.0 \pm 18.5^{\mathrm{a}}(35)$ & $22.4 \pm 3.0^{\mathrm{b}}(13)$ \\
R3 & $178.5 \pm 26.3^{\mathrm{a}}$ & $94.1 \pm 7.9^{\mathrm{a}}(51)$ & $64.7 \pm 19.4^{\mathrm{a}}(35)$ & $25.8 \pm 2.5^{\mathrm{a}}(14)$ \\
Faeces & 125.0 & $80.4(64)$ & $21.2(17)$ & $23.3(19)$ \\
\hline
\end{tabular}

where a significant $(P=0.001)$ decrease from $9.4 \pm 0.4$ to $7.9 \pm 0.4 \log _{10}\left(\mathrm{MCN} \mathrm{ml}^{-1}\right)$ was measured. MCN ranges of bacterial groups measured during Stab in the effluents of the different reactors were similar to those of the faecal inoculum, except for Enterobacteriaceae, for which the MCN values were about $3 \log$ units higher than for the faecal inoculum.

Salmonella addition to F1 and F2 had no significant $(P>0.05)$ effects on Bifidobacterium spp. and Enterobacteriaceae populations, but was accompanied by a significant increase of Lactobacillus/Leuconostoc/Pediococcus spp. counts, from $3.4 \pm 0.3$ (Stab) to $4.4 \pm 0.5(\mathrm{Sal}) \log _{10}\left(\mathrm{MCN} \mathrm{ml}^{-1}\right)$ in $\mathrm{F} 1$ $(P=0.003)$ and from $3.2 \pm 0.3$ (Stab) to $4.3 \pm 0.6$ (Sal) $\log _{10}\left(\mathrm{MCN} \mathrm{ml}^{-1}\right)$ in F2 $(P=0.012)$.

Effects of $\boldsymbol{E}$. coli L1000. No significant $(P>0.05)$ changes of Bifidobacterium spp. and Enterobacteriaceae populations were measured during the first E. coli L1000 treatments [Ecol I (F1) and $\left.\mathrm{Ecol}^{\star} \mathrm{I}(\mathrm{F} 2)\right]$, and MCN values of E. coli L1000 were 3-5 log units lower compared with total Enterobacteriaceae. MCN values for Lactobacillus/Leuconostoc/Pediococcus spp. increased significantly $(P<0.0001)$ with the first addition of $E$. coli L1000 wt (F1, + 1 log unit) or MccB17- (F2, + 0.8 log unit) to levels similar $(P>0.05)$ to those measured in the faecal inoculum $\left[5.1 \log _{10}\left(\mathrm{MCN} \mathrm{ml}^{-1}\right)\right]$. No significant population changes were detected after the second addition of E. coli L1000, except for a small but significant $(P=0.032)$ increase of Enterobacteriaceae from $8.3 \pm 0.3\left(\right.$ Ecol $\left.^{\star} \mathrm{I}\right)$ to $8.7 \pm 0.2$ $\log _{10}\left(\mathrm{MCN} \mathrm{ml}^{-1}\right)\left(\right.$ Ecol$\left.^{\star} \mathrm{II}\right)$ in $\mathrm{F} 2$.

Effects of $B$. thermophilum RBL67. The first addition of B. thermophilum RBL67 to F1 (Bif I) and F2 (Bif) had no significant $(P>0.05)$ effects on Bifidobacterium spp. and Enterobacteriaceae populations. Counts of $B$. thermophilum RBL67 during these periods were equal to total Bifidobacterium spp. counts. Lactobacillus/Leuconostoc/Pediococcus counts increased significantly $(P=0.032)$ only in F2 compared with the previous Ecol ${ }^{\star}$ II period, and stabilized at $5.8 \pm 0.3 \log _{10}\left(\mathrm{MCN} \mathrm{ml}^{-1}\right)$ (Bif I, Bif) in both F1 and F2. In contrast, the second addition of B. thermophilum RBL67 in F1 (Bif II) was accompanied by a small $(P=0.029)$ decrease of Bifidobacterium spp. from $6.8 \pm 0.3$ (Bif I) to $6.4 \pm 0.2$ (Bif II) $\log _{10}\left(\mathrm{MCN} \mathrm{ml}^{-1}\right)$ and a significant $(P<0.0001)$ increase of Lactobacillus/Leuconostoc/Pediococcus spp. from $5.7 \pm 0.3$ (Bif I) to $6.7 \pm 0.2$ (Bif II) $\log _{10}\left(\mathrm{MCN} \mathrm{ml}^{-1}\right)$.

Effects of inulin. Inulin addition in F2 resulted in a sharp and significant $(P<0.0001)$ increase of both Lactobacillus/ Leuconostoc/Pediococcus spp. and Bifidobacterium spp. populations [ $>2$ and $1.5 \log _{10}\left(\mathrm{MCN} \mathrm{ml}^{-1}\right)$, respectively, in all reactors], concomitant with $B$. thermophilum RBL67 counts.

\section{Effects of probiotic and prebiotic treatments on gut metabolic activity}

No periodic effects (except for inulin addition) were detected on SCFA concentrations and ratios measured by HPLC. Therefore, mean SCFA concentrations and ratios calculated for the last 3 days of all experimental periods for different reactors are presented in Table 4. Stable levels of total SCFA concentrations were measured in all reactors for both F1 and F2, with increasing values from the proximal (R1) to the distal (R3) colonic reactors. SCFA concentrations and ratios were similar for F1 and F2 (with the exception of the last inulin period; Table 4). Inulin addition in F2 led to a significant $(P<0.05)$ increase in butyrate from $46.8 \pm 0.9,54.3 \pm 1.5$ and $52.4 \pm 0.5 \mathrm{mmol}^{-1}$ to $88.4 \pm 1.8$, $105.1 \pm 6.0$ and $101.1 \pm 3.8 \mathrm{mmol}^{-1}$ in R1, R2 and R3, respectively. Butyrate accounted for approximately $50 \%$ of total SCFA compared with only $35 \%$ during the previous Bif period. A concomitant reduction in proportion of acetate from 56 to $44 \%$ was measured, whereas propionate remained unchanged.

\section{DISCUSSION}

The development of biological alternatives to antibiotics in order to treat infections and address the increasing 
prevalence of antibiotic-resistant and highly invasive pathogenic bacteria is of high public interest. Probiotic bacteria have great potential to complement or substitute conventional antibiotic treatments. Beneficial properties such as anti-Salmonella activity are, however, strainspecific and must be assessed separately for each probiotic bacterium. Two promising probiotic strains isolated from human faeces were tested in this study, E. coli L1000 and B. thermophilum RBL67 (von Ah et al., 2007; Zihler et al., 2009). These have been shown to produce proteinaceous antimicrobial compounds with high and broad activity against Salmonella when assessed with simple antagonistic tests.

The human colon constitutes a protective and nutrientrich habitat for trillions of bacteria living in symbiosis with the host (Gaskins et al., 2008). This dense and hostdependent microbial community has established an ecological mutualism with the host that confers a powerful barrier effect against pathogenic invaders, referred to as colonization resistance (Barth et al., 2009). The ability to protect the host from invading pathogens presupposes that probiotics are able to transiently occupy a specific ecological niche in adequate numbers for optimal functionality. Barth et al. (2009) were able to show recently that the probiotic E. coli strain Nissle 1917 producing colicin has the capacity to adapt easily to the intestinal milieu of healthy conventional piglets, allowing persistence and replication in the gut. There are, however, no studies investigating the competitiveness of bacteriocinogenic strains compared with negative mutants for intestinal colonization and efficacy to counteract pathogens. In our study, E. coli L1000, independently of the presence of genetic determinants for microcin B17 production, was not able to colonize in vitro a complex gut microbiota at a high level $\left[\leqslant 5.8 \log _{10}\left(\mathrm{MCN} \mathrm{ml}^{-1}\right)\right.$ during the Ecol periods], even after high inoculation with $6 \times 10^{9}$ cells immobilized in beads to induce colonization. This addition considerably exceeds the colonic delivery of probiotics at the recommended daily dose of $10^{8}-10^{9}$ cells believed to exert a beneficial effect on the host (Gill \& Prasad, 2008), while accounting for the potentially high viability loss during passage through the upper gastrointestinal tract. Accordingly, E. coli L1000 addition did not significantly affect gut microbiota composition or metabolic activity, except for an increase of the Lactobacillus/Leuconostoc/ Pediococcus population, although it strongly stimulated Salmonella growth. It has been previously shown that addition of Salmonella to a proximal reactor of an in vitro intestinal colonic fermentation model with immobilized child faecal microbiota stimulates the growth of the Clostridium coccoides-Eubacterium rectale group (Le Blay et al., 2009), which also belongs to the phylum Firmicutes. The inability of E. coli L1000 to stabilize at high levels in our model could also be explained by the high levels of Enterobacteriaceae with similar environmental requirements in the intestinal ecosystem of the donor. Microcin B17 production did not confer a significant ecological advantage upon E. coli L1000 wt over other Enterobacteriaceae, although microcin $\mathrm{B} 17$ has been shown to be active against Salmonella and other Enterobacteriaceae (Pons et al., 2002). However, the E. coli L1000 wt population was significantly higher in R2 and R3 after the first inoculation of the strain in R1 (Ecol I) compared with the bacteriocin-negative mutant $\left(\right.$ Ecol $\left.^{\star} \mathrm{I}\right)$, possibly due to in situ microcin B17 production. Stecher et al. (2010) have recently provided evidence that the presence of closely related strains can enhance the possibility of invasion of exogenous bacteria into the gut ecosystem. Mice harbouring high levels of gut lactobacilli are more efficiently colonized by a commensal and orally administered Lactobacillus reuter ${ }^{\mathrm{RR}}$ strain. In addition, those authors provide evidence that individuals with high commensal Enterobacteriaceae densities are more susceptible to Salmonella-induced gut inflammation. Our data that show a stimulation of Salmonella growth after addition of E. coli L1000 to a gut microbiota already highly colonized with Enterobacteriaceae support this mechanism.

In contrast to E. coli L1000, B. thermophilum RBL67 colonized the intestinal microbiota at high levels after the first addition and accounted for a very high proportion $(\sim 70 \%)$ of the total bifidobacteria population. In a previous study, we showed that $B$. thermophilum RBL67 added to a reactor simulating a child proximal colon made up to $12 \%$ of total bifidobacteria (A. Zihler and others, unpublished results). Although the metabolic activity and composition of the intestinal ecosystem were little changed upon $B$. thermophilum RBL67 addition, a significant decrease in bifidobacteria counts was observed, possibly explained by thermophilicin B67 production affecting closely related bacteria. In addition, B. thermophilum RBL67 was highly active against $S$. Typhimurium M557, when added to the reactor preventively before or curatively after Salmonella colonization. Compared with the present study, Salmonella counts were about $1.5 \log$ units lower before the addition of strain RBL67. Therefore, very different $B$. thermophilum RBL67: Salmonella ratios (3050:1 and 2:1, respectively) were reached. The determination of the required probiotic dose for a targeted anti-pathogenic effect is difficult because the optimal concentration depends on several factors, including the probiotic organism, duration of application, delivery matrix (food or pharmaceutical) and the targeted population group (de Vrese \& Schrezenmeir, 2008). For example, a dose-efficacy study revealed that a 1-week Lactobacillus rhamnosus GG (LGG) treatment was equally effective at two dosages $\left(10^{10}\right.$ and $10^{12}$ c.f.u. twice per day) in decreasing the frequency and duration of rotavirus-induced acute watery diarrhoea in Indian children (Basu et al., 2009), although data on the LGG: rotavirus ratios in the gut are lacking. To our knowledge, no study has investigated probiotic: pathogen ratios in the gut for maximal enteric protection, especially against Salmonella.

Inulin addition produced a large increase of lactobacilli counts and a pronounced bifidogenic effect accompanied by a shift in SCFA ratios towards elevated butyrate levels, as observed in previous studies (Kleessen et al., 2001; 
Langlands et al., 2004; Le Blay et al., 2009). Interestingly, addition of inulin also led to a sharp increase of $B$. thermophilum RBL67 counts in all three reactors, and stimulated the growth of Salmonella in the distal colon reactor R3. Several studies have reported a correlation between the administration of different prebiotics (including inulin) and an enhanced severity of Salmonella infection in rats and mice (Bovee-Oudenhoven et al., 2003; Petersen et al., 2009; Ten Bruggencate et al., 2003, 2004) with increased translocation of Salmonella, although these effects are not always correlated with an enhanced pathogen colonization of the gut.

In conclusion, data obtained with our in vitro intestinal fermentation model of Salmonella colonization in the child colon reflect a lack of efficacy of microcin B17-producing E. coli L1000 to inhibit Salmonella, in contrast to the high efficacy displayed by this strain in simple in vitro antagonistic tests (Zihler et al., 2009). Although simple in vitro activity assays are practical and useful for first screening of probiotics active against Salmonella, more complete models reflecting the complex gut microbiota and environments are required to assess their efficacy and provide information on the mechanisms of probiotics for enteric protection within a complex microbial ecosystem. This validation step is important before considering in vivo testing with animal models. Indeed, several biotic factors are difficult to reproduce in vitro, and especially host immune and neuroendocrine responses are lacking in in vitro colonic fermentation models. Therefore, we are currently testing with intestinal epithelial cell models the in vitro effects on the host cell response of effluent samples produced by the colonic fermentation model and containing a child gut microbiota, Salmonella and probiotics. Such combined in vitro models could provide a more complete assessment of the potential and mechanisms of probiotics against pathogen infection in the gut.

\section{ACKNOWLEDGEMENTS}

This study was supported by a grant from the Swiss National Science Foundation (SNF; project number 3100170-114028).

\section{REFERENCES}

Barth, S., Duncker, S., Hempe, J., Breves, G., Baljer, G. \& Bauerfeind, R. (2009). Escherichia coli Nissle 1917 for probiotic use in piglets: evidence for intestinal colonization. J Appl Microbiol 107, 1697-1710.

Bartosch, S., Fite, A., Macfarlane, G. T. \& McMurdo, M. E. (2004). Characterization of bacterial communities in feces from healthy elderly volunteers and hospitalized elderly patients by using real-time PCR and effects of antibiotic treatment on the fecal microbiota. Appl Environ Microbiol 70, 3575-3581.

Basu, S., Paul, D. K., Ganguly, S., Chatterjee, M. \& Chandra, P. K. (2009). Efficacy of high-dose Lactobacillus rhamnosus GG in controlling acute watery diarrhea in Indian children: a randomized controlled trial. J Clin Gastroenterol 43, 208-213.
Bovee-Oudenhoven, I. M., ten Bruggencate, S. J., Lettink-Wissink, M. L. \& van der Meer, R. (2003). Dietary fructo-oligosaccharides and lactulose inhibit intestinal colonisation but stimulate translocation of Salmonella in rats. Gut 52, 1572-1578.

Cinquin, C., Le Blay, G., Fliss, I. \& Lacroix, C. (2006). New three-stage in vitro model for infant colonic fermentation with immobilized fecal microbiota. FEMS Microbiol Ecol 57, 324-336.

Cleusix, V., Lacroix, C., Vollenweider, S. \& Le Blay, G. (2008). Glycerol induces reuterin production and decreases Escherichia coli population in an in vitro model of colonic fermentation with immobilized human feces. FEMS Microbiol Ecol 63, 56-64.

Cleusix, V., Lacroix, C., Dasen, G., Leo, M. \& Le Blay, G. (2010). Comparative study of a new quantitative real-time PCR targeting the xylulose-5-phosphate/fructose-6-phosphate phosphoketolase bifidobacterial gene $(x f p)$ in faecal samples with two fluorescence in situ hybridization methods. J Appl Microbiol 108, 181-193.

Collado, M. C., Isolauri, E., Salminen, S. \& Sanz, Y. (2009). The impact of probiotic on gut health. Curr Drug Metab 10, 68-78.

Corr, S. C., Li, Y., Riedel, C. U., O'Toole, P. W., Hill, C. \& Gahan, C. G. (2007). Bacteriocin production as a mechanism for the antiinfective activity of Lactobacillus salivarius UCC118. Proc Natl Acad Sci U S A 104, 7617-7621.

Corr, S. C., Hill, C. \& Gahan, C. G. (2009). Understanding the mechanisms by which probiotics inhibit gastrointestinal pathogens. Adv Food Nutr Res 56, 1-15.

Crum-Cianflone, N. F. (2008). Salmonellosis and the gastrointestinal tract: more than just peanut butter. Curr Gastroenterol Rep 10, 424431.

Dabour, N., Zihler, A., Kheadr, E., Lacroix, C. \& Fliss, I. (2009). In vivo study on the effectiveness of pediocin PA-1 and Pediococcus acidilactici UL5 at inhibiting Listeria monocytogenes. Int J Food Microbiol 133, 225-233.

de Vrese, M. \& Schrezenmeir, J. (2008). Probiotics, prebiotics, and synbiotics. Adv Biochem Eng Biotechnol 111, 1-66.

Fallingborg, J., Christensen, L. A., Ingeman-Nielsen, M., Jacobsen, B. A., Abildgaard, K., Rasmussen, H. H. \& Rasmussen, S. N. (1990). Measurement of gastrointestinal $\mathrm{pH}$ and regional transit times in normal children. J Pediatr Gastroenterol Nutr 11, 211-214.

Furet, J. P., Firmesse, O., Gourmelon, M., Bridonneau, C., Tap, J., Mondot, S., Doré, J. \& Corthier, G. (2009). Comparative assessment of human and farm animal faecal microbiota using real-time quantitative PCR. FEMS Microbiol Ecol 68, 351-362.

Gaskins, H. R., Croix, J. A., Nakamura, N. \& Nava, G. M. (2008). Impact of the intestinal microbiota on the development of mucosal defense. Clin Infect Dis 46 (Suppl. 2), S80-S86.

Gill, H. \& Prasad, J. (2008). Probiotics, immunomodulation, and health benefits. Adv Exp Med Biol 606, 423-454.

Guo, X., Xia, X., Tang, R., Zhou, J., Zhao, H. \& Wang, K. (2008). Development of a real-time PCR method for Firmicutes and Bacteroidetes in faeces and its application to quantify intestinal population of obese and lean pigs. Lett Appl Microbiol 47, 367373.

Hapfelmeier, S., Ehrbar, K., Stecher, B., Barthel, M., Kremer, M. \& Hardt, W. D. (2004). Role of the Salmonella pathogenicity island 1 effector proteins SipA, SopB, SopE, and SopE2 in Salmonella enterica subspecies 1 serovar Typhimurium colitis in streptomycin-pretreated mice. Infect Immun 72, 795-809.

Kheadr, E., Zihler, A., Dabour, N., Lacroix, C., Le Blay, G. \& Fliss, I. (2010). Study of the physicochemical and biological stability of pediocin PA-1 in the upper gastrointestinal tract conditions using a dynamic in vitro model. J Appl Microbiol 109, 54-64. 
Kingsley, R. A., Msefula, C. L., Thomson, N. R., Kariuki, S., Holt, K. E., Gordon, M. A., Harris, D., Clarke, L., Whitehead, S. \& other authors (2009). Epidemic multiple drug resistant Salmonella Typhimurium causing invasive disease in sub-Saharan Africa have a distinct genotype. Genome Res 19, 2279-2287.

Kleessen, B., Hartmann, L. \& Blaut, M. (2001). Oligofructose and long-chain inulin: influence on the gut microbial ecology of rats associated with a human fecal flora. Br J Nutr 86, 291-300.

Langlands, S. J., Hopkins, M. J., Coleman, N. \& Cummings, J. H. (2004). Prebiotic carbohydrates modify the mucosa associated microflora of the human large bowel. Gut 53, 1610-1616.

Le Blay, G., Rytka, J., Zihler, A. \& Lacroix, C. (2009). New in vitro colonic fermentation model for Salmonella infection in the child gut. FEMS Microbiol Ecol 67, 198-207.

Macfarlane, G. T., Macfarlane, S. \& Gibson, G. R. (1998). Validation of a three-stage compound continuous culture system for investigating the effect of retention time on the ecology and metabolism of bacteria in the human colon. Microb Ecol 35, 180-187.

Mathys, S., Lacroix, C., Mini, R. \& Meile, L. (2008). PCR and real-time PCR primers developed for detection and identification of Bifidobacterium thermophilum in faeces. BMC Microbiol 8, 179.

Michel, C., Kravtchenko, T. P., David, A., Gueneau, S., Kozlowski, F. \& Cherbut, C. (1998). In vitro prebiotic effects of Acacia gums onto the human intestinal microbiota depends on both origin and environmental pH. Anaerobe 4, 257-266.

Ohl, M. E. \& Miller, S. I. (2001). Salmonella: a model for bacterial pathogenesis. Annu Rev Med 52, 259-274.

Petersen, A., Heegaard, P. M., Pedersen, A. L., Andersen, J. B., Sørensen, R. B., Frøkiaer, H., Lahtinen, S. J., Ouwehand, A. C., Poulsen, M. \& Licht, T. R. (2009). Some putative prebiotics increase the severity of Salmonella enterica serovar Typhimurium infection in mice. BMC Microbiol 9, 245.

Pons, A. M., Lanneluc, I., Cottenceau, G. \& Sable, S. (2002). New developments in non-post translationally modified microcins. Biochimie 84, 531-537.

Ramirez-Farias, C., Slezak, K., Fuller, Z., Duncan, A., Holtrop, G. \& Louis, P. (2009). Effect of inulin on the human gut microbiota: stimulation of Bifidobacterium adolescentis and Faecalibacterium prausnitzii. Br J Nutr 101, 541-550.

Stecher, B. \& Hardt, W. D. (2008). The role of microbiota in infectious disease. Trends Microbiol 16, 107-114.

Stecher, B., Chaffron, S., Kappeli, R., Hapfelmeier, S., Freedrich, S., Weber, T. C., Kirundi, J., Suar, M., McCoy, K. D. \& other authors (2010). Like will to like: abundances of closely related species can predict susceptibility to intestinal colonization by pathogenic and commensal bacteria. PLoS Pathog 6, e1000711.

Ten Bruggencate, S. J., Bovee-Oudenhoven, I. M., Lettink-Wissink, M. L. \& Van der Meer, R. (2003). Dietary fructo-oligosaccharides dosedependently increase translocation of salmonella in rats. J Nutr 133, 2313-2318.

Ten Bruggencate, S. J., Bovee-Oudenhoven, I. M., Lettink-Wissink, M. L., Katan, M. B. \& Van Der Meer, R. (2004). Dietary fructooligosaccharides and inulin decrease resistance of rats to salmonella: protective role of calcium. Gut 53, 530-535.

Viswanathan, V. K., Hodges, K. \& Hecht, G. (2009). Enteric infection meets intestinal function: how bacterial pathogens cause diarrhoea. Nat Rev Microbiol 7, 110-119.

von Ah, U. (2006). Identification of Bifidobacterium thermophilum RBL67 isolated from baby faeces and partial purification of its bacteriocin. Dissertation no. 16927, ETH Zurich, Zurich, Switzerland.

von Ah, U., Mozzetti, V., Lacroix, C., Kheadr, E. E., Fliss, I. \& Meile, L. (2007). Classification of a moderately oxygen-tolerant isolate from baby faeces as Bifidobacterium thermophilum. BMC Microbiol 7, 79.

Wagener, S., Shankar, K. R., Turnock, R. R., Lamont, G. L. \& Baillie, C. T. (2004). Colonic transit time - what is normal? J Pediatr Surg 39, 166-169.

Zihler, A., Le Blay, G., de Wouters, T., Lacroix, C., Braegger, C. P., Lehner, A., Tischler, P., Rattei, T., Hächler, H. \& Stephan, R. (2009). In vitro inhibition activity of different bacteriocin-producing Escherichia coli against Salmonella strains isolated from clinical cases. Lett Appl Microbiol 49, 31-38.

Edited by: H. J. Flint 